\title{
Transparency and Reputation: \\ The Publication of Central Bank Forecasts
}

\author{
Petra M. Geraats
}

December 2004

CWPE 0473

Not to be quoted without permission 


\begin{abstract}
:
Transparency has become one of the key features of monetary policy. This paper analyzes the reputational incentives related to transparency, focusing on the publication of central bank forecasts. A simple dynamic monetary policy game shows how transparency reduces inflation, as has been found empirically. Although transparency exposes weak central banks, the negative market feedback in response to secrecy could provide a sufficiently strong inducement to become transparent. Thus, reputational concerns could lead to transparency, even without formal disclosure requirements. Keywords: transparency, monetary policy, central bank forecasts.

JEL codes: D82, E42, E52, E58.
\end{abstract}




\section{Transparency and Reputation: The Publication of Central Bank Forecasts ${ }^{1}$}

Petra M. Geraats ${ }^{2}$

\section{Introduction}

Transparency has become one of the key features of monetary policy. A comprehensive survey of 94 central banks by Fry, Julius, Mahadeva, Roger and Sterne (2000) reveals that $74 \%$ of central banks consider transparency a vital or very important component of their monetary policy framework, and that $78 \%$ publish forwardlooking analysis. This paper analyzes the reputational incentives associated with transparency, focusing on the publication of central bank forecasts. It predicts a negative relation between transparency and inflation, as has been found empirically. In addition, it helps to explain why transparency (in monetary policy, but also in other contexts) often goes beyond formal disclosure requirements.

More precisely, the paper shows how transparency about economic forecasts improves the central bank's incentive to build reputation. Intuitively, the interest rate set by the central bank reflects both it inflationary intentions and the economic shocks it anticipates. Under transparency, people observe the central bank's economic forecasts, so the interest rate provides a more accurate signal of the central bank's intentions. This makes the expectations of the public more responsive to the central bank's attempt to build reputation through higher interest rates. So, transparency improves the central bank's ability to gain and maintain reputation. In addition, since the market pays more attention to the signals from transparent

\footnotetext{
${ }^{1}$ This paper is an abridged version of my job market paper (Geraats 2000), which benefitted from discussions with numerous people and was presented at a dozen seminars and conferences. I extend special thanks to my dissertation advisors, Maury Obstfeld, David Romer and Rich Lyons, for valuable comments.

${ }^{2}$ Faculty of Economics, University of Cambridge, Cambridge, CB3 9DD, United Kingdom. Email: Petra.Geraats@econ.cam.ac.uk
} 
central banks, they invest more in reputation. This leads to a lower inflation bias, which is socially beneficial.

Nevertheless, a weak, inflationary central bank prefers opacity about its forecasts because it obscures its true intent. However, when the choice of transparency is endogenous, secrecy is associated with weakness and harms a central bank's reputation. This negative market feedback could be sufficient to induce all central banks to adopt transparency. This mechanism applies more generally and is useful to understand how (international) financial markets could impose transparency in other contexts.

The model in this paper is in the tradition of the discretionary monetary policy games first described by Kydland and Prescott (1977) and later formalized by Barro and Gordon (1983). It is a simple two-period model in which there is some uncertainty about the central bank's preferences and the central bank has a motive to stimulate output beyond the natural rate. In contrast to most previous models, there is a real interest rate transmission mechanism, so the nominal interest rate acts as both the policy instrument and a signal of the central bank's intentions. In addition, there is an explicit distinction between a regime of opacity and transparency. The latter corresponds to the publication of central bank forecasts, which reveals the economic disturbances to which policymakers respond and allows the public to infer the central bank's intentions from the policy instrument.

In a more general context, transparency refers to the absence of information asymmetries. This paper builds on insights from information economics (see Stiglitz (2000) for a recent overview) and contributes to the literature on transparency of monetary policy by incorporating both a reputation and a self-selection/signaling effect.

First, transparency affects the central bank's incentive to build reputation. There is rational updating of the central bank's type based on observable policy actions, similar to Backus and Driffill 
(1985), Barro (1986) and Cukierman and Meltzer (1986). The result that transparency leads to greater sensitivity of inflation expectations and reduces the inflation bias is common to Faust and Svensson (2001) and Jensen $(2002,2000)$. However, they consider inference based on policy outcomes (complicated by unanticipated monetary control errors), whereas the present paper focuses on the private sector response to policy actions (which reflect anticipated economic shocks). This is motivated by the fact that interest rate decisions are scrutinized by the market for clues about future monetary policy. In addition, it helps to explain why central banks tend to publish forecasts for both inflation and output, which is puzzling in light of the literature on inflation-forecast targeting (e.g. Svensson 1997).

Second, a novel effect analyzed in this paper is that the choice of transparency gives rise to signaling and self-selection. When the transparency regime is endogenous, the public rationally expects opaque central banks to be more inflationary, which harms their reputation and leads to higher inflation expectations. The result that market discipline could lead to transparency because of reputational concerns is shown to hold for a reduced-form payoff function that is more widely applicable.

The burgeoning theoretical literature on transparency of monetary policy has obtained a variety of findings, depending on the assumptions of the model and the particular information asymmetry under consideration. A comprehensive survey is provided by Geraats (2002). The present paper is about 'economic transparency', the disclosure of the economic information that is used for policy decisions, in particular central bank forecasts. Tarkka and Mayes (1999) argue that the publication of central bank forecasts could reduce (mutual) uncertainty about expectations and lead to greater predictability of monetary policy. On the other hand, Gersbach (1998), Cukierman (2001) and Jensen (2000) show that transparency about economic disturbances could hamper stabilization policy when 
the disclosure of shocks leads to an adjustment of inflation expectations that negatively affects the current output-inflation tradeoff. Jensen (2000) adopts a new-Keynesian Phillips curve, whereas Gersbach (1998) and Cukierman (2001) use a neo-monetarist Lucastype transmission mechanism in which (central bank forecasts of) economic disturbances are observed before private sector inflation expectations are fixed.

In contrast to Gersbach (1998) and Cukierman (2001), the present paper assumes that there is some preference uncertainty which gives rise to a beneficial incentive effect of transparency that reduces the inflation bias. A similar result is found by Faust and Svensson (2001) and Jensen (2002) who focus on a different kind of transparency, the disclosure of information on monetary control errors. Although Faust and Svensson (2001) find that increased transparency of control errors tends to improve social welfare, Faust and Svensson (2002) argue that minimum transparency is a likely outcome in practice when the regime is endogenous. However, they do not consider self-selection effects, which could provide a powerful incentive for central banks to adopt transparency.

The analysis in this paper relies on three important presumptions. First, there is uncertainty about the central bank's intentions. For analytical convenience this is modeled as uncertainty about the inflation target. Although many central banks have announced explicit inflation targets, these are often formulated as ranges. Moreover, they need not be perfectly credible. Bernanke, Laubach, Mishkin and Posen (1999) provide anecdotal support for this by showing that explicit inflation targets affect inflation expectations only gradually. In fact, there is always likely to be some uncertainty about the central bank's intentions because they cannot be directly observed and may change over time.

Second, it is assumed that there is asymmetric information about economic disturbances. Romer and Romer (2000) present 
empirical evidence for this. They show that confidential Federal Reserve forecasts of inflation are superior to commercial forecasts, even at a short horizon of one or two quarters ahead. This suggests that the central bank has private information about economic disturbances. This could be due to confidential information not available to the private sector, like bank supervisory data (Peek, Rosengren and Tootell 1999), or the economic analysis by central bank staff. Although the present model assumes that the central bank has more accurate information, the conclusions even hold when the private sector is merely unsure of the central bank's forecasts of economic shocks.

Finally, it is assumed that central bank forecasts are truthful and that people are able to interpret them correctly. Instead, Winkler (2002) argues that effective communication is not trivial; he proposes to view transparency in terms of openness, clarity, honesty and common understanding. In addition, Garfinkel and Oh (1995) assume that central bank forecasts cannot be verified and show how a central bank could partially reveal its private information through noisy announcements. The present paper adopts the approach proposed by Goodfriend (1986, p. 86) and assumes that the data collection, modeling and forecasting activities performed by central bank staff are delegated to an independent agency that reports to both monetary policymakers and the public in the case of transparency. Thus, the forecasts are in principle verifiable.

An alternative to transparency that reduces the inflation bias would be the implementation of an instrument rule that incorporates the central bank's information on economic disturbances. However, central banks appear extremely reluctant to adopt instrument rules. One reason is that rules do not allow a central bank to respond to unforeseen contingencies or changes in the structure of the economy. Instead, many central banks appear to conduct discretionary policy under transparency, which yields a lower inflation bias with- 
out giving up control.

The next section presents the model, which is analyzed first for an exogenous regime of transparency and opacity in section 3, and subsequently for the endogenous choice of regime in section 4 . The robustness of the results and empirical evidence are discussed in section 5, and section 6 concludes.

\section{Model}

The central banker is in office for two periods and maximizes the expected value of the objective function

$$
U=W_{1}+\delta W_{2}
$$

where $\delta$ is the subjective discount factor $(0<\delta<1)$, and

$$
W_{t}=-\frac{1}{2}\left(\pi_{t}-\tau\right)^{2}+\beta\left(y_{t}-\bar{y}\right),
$$

where $\pi_{t}$ is inflation; $y_{t}$ is the level of aggregate real output; $\tau$ is the implicit inflation target, drawn from the (nondegenerate) normal distribution: $\tau \sim N\left(\bar{\tau}, \sigma_{\tau}^{2}\right)$ with $\sigma_{\tau}^{2}>0 ; \bar{y}$ equals the natural rate of output; $\beta$ is the relative weight on output stimulation $(\beta>0)$; and the subscript $t$ denotes the time period, $t \in\{1,2\}$. The economy is described by two equations. Aggregate demand is given by the IS relationship

$$
y_{t}=\bar{y}-\left(i_{t}-\pi_{t}^{e}-\bar{r}\right)+d_{t},
$$

where $i_{t}$ is the nominal interest rate; $\pi_{t}^{e}$ denotes the market's inflation expectations; $\bar{r}$ is the long-run, ex ante real interest rate; and, $d_{t}$ is a white noise demand shock: $d_{t} \sim N\left(0, \sigma_{d}^{2}\right)$ with $\sigma_{d}^{2}>0$. Aggregate supply is given by the price adjustment equation

$$
\pi_{t}=\pi_{t}^{e}+\left(y_{t}-\bar{y}\right)-s_{t},
$$

where $s_{t}$ is a white noise supply shock: $s_{t} \sim N\left(0, \sigma_{s}^{2}\right)$ with $\sigma_{s}^{2}>0$. For analytical convenience, it is assumed that $s_{t}, d_{t}$ and $\tau$ are 
independent. Without loss of generality, the slopes of the aggregate demand and supply relations (3) and (4) are normalized to one.

The monetary policy instrument is the nominal interest rate $i_{t}$, following the actual practice of most central banks. The public fixes its inflation expectations $\pi_{t}^{e}$, so the central bank is able to influence the ex ante real interest rate $i_{t}-\pi_{t}^{e}$. As a result, monetary policy has real effects. Inflation can be indirectly controlled through the output gap $y_{t}-\bar{y}$.

The timing is as follows. Before the first period, the inflation target $\tau$ is drawn, but only known to the central bank. Subsequently, the central bank chooses a regime of transparency $(T)$ or opacity $(O)$ about the economic shocks $d_{t}$ and $s_{t}$ that the central bank responds to. The public perceives the chosen regime and forms its inflation expectations $\pi_{1}^{e}$. In the beginning of the first period, the economic disturbances $d_{1}$ and $s_{1}$ are realized. The central bank observes $\pi_{1}^{e}, d_{1}$ and $s_{1}$, and subsequently sets the nominal interest rate $i_{1} .{ }^{3}$ At the end of the first period, the public forms inflation expectations $\pi_{2}^{e}$, using the interest rate $i_{1}$ (and under transparency, $d_{1}$ and $s_{1}$ ) to update its prior on $\tau$. At the beginning of the second period, inflation $\pi_{1}$ and output $y_{1}$ are observed and the shocks $d_{2}$ and $s_{2}$ are realized. The central bank perceives $\pi_{2}^{e}, d_{2}$ and $s_{2}$, and determines the interest rate $i_{2}$. After this last period, inflation $\pi_{2}$ and output $y_{2}$ are observed.

The model features asymmetric information. The public is uncertain about the central bank's inflation target $\tau$. In addition, it does not know the shocks $d_{t}$ and $s_{t}$ when it forms its inflation expectations $\pi_{t}^{e}$. It is assumed that the public has rational expectations. Formally, the information set available to the public when it forms its inflation expectations $\pi_{1}^{e}$ equals $\Omega_{0}^{R} \equiv\left\{R, \beta, \bar{y}, \bar{r}, \bar{\tau}, \sigma_{\tau}^{2}, \sigma_{d}^{2}, \sigma_{s}^{2}\right\}$ under transparency $(R=T)$ and opacity $(R=O)$. When the public forms its inflation expectations $\pi_{2}^{e}$, the available information set

\footnotetext{
${ }^{3}$ For simplicity, the model assumes that the central bank is able to forecast the economic shocks $d_{t}$ and $s_{t}$ perfectly. It is straightforward to extend the model to allow for forecast errors, but this does not affect any of the qualitative results.
} 
equals $\left\{i_{1}, \Omega_{1}^{R}\right\}$, where $\Omega_{1}^{T} \equiv\left\{d_{1}, s_{1}, \Omega_{0}^{T}\right\}$ under transparency and $\Omega_{1}^{O} \equiv \Omega_{0}^{O}$ under opacity. Comparing transparency with opacity, the only difference is that in the case of transparency the public observes the economic disturbances to which the central bank reacts.

The public uses the interest rate $i_{1}$ to infer the central bank's inflation target $\tau$. It is assumed that inflation $\pi_{1}$ and output $y_{1}$ are not observed until after inflation expectations $\pi_{2}^{e}$ are formed because of lags in monetary policy transmission. This captures the fact that in practice, changes in the policy instrument only have an effect on macroeconomic outcomes after a substantial delay. Meanwhile, people adjust their expectations based on the policy instrument, which sets the stage for the next policy decision.

The model is solved in two steps. In section 3, the transparency regime is assumed to be exogenous. In section 4, the choice of regime is endogenous.

\section{Exogenous Regime}

The case of an exogenous transparency regime is interesting in itself because central banks tend to be subject to some legislative disclosure requirements. Exogeneity of the regime precludes selfselection, so it is assumed that the public's prior on the inflation target is $\bar{\tau}$ under both transparency and opacity.

The problem can be solved by backwards induction. In period two, the central bank maximizes $W_{2}$ with respect to $i_{2}$ subject to (4) and (3), and given $\pi_{2}^{e}, d_{2}$ and $s_{2}$. The first order condition implies

$$
i_{2}=\bar{r}+\pi_{2}^{e}-\left(\tau+\beta-\pi_{2}^{e}\right)+d_{2}-s_{2} .
$$

The nominal interest rate $i_{2}$ (and the ex ante real interest rate $\left.i_{2}-\pi_{2}^{e}\right)$ is increasing in the market's inflation expectations $\pi_{2}^{e}$ and the demand shock $d_{2}$, but decreasing in the supply shock $s_{2}$. 
Substituting (5) into (3) and (4) yields

$$
\begin{aligned}
& y_{2}=\bar{y}+\left(\tau+\beta-\pi_{2}^{e}\right)+s_{2} \\
& \pi_{2}=\tau+\beta .
\end{aligned}
$$

Output $y_{2}$ is decreasing in inflation expectations $\pi_{2}^{e}$ and increasing in the output supply shock $s_{2}$. The demand shock $d_{2}$ is completely offset by monetary policy. Since the objective function is linear in output, the supply shock $s_{2}$ does not influence the level of inflation $\pi_{2}$ and there is an inflationary bias $\left(\pi_{2}>\tau\right)$ of discretionary monetary policy. Substituting (7) and (6) into (2) gives

$$
W_{2}=\frac{1}{2} \beta^{2}+\beta\left(\tau-\pi_{2}^{e}\right)+\beta s_{2} .
$$

This shows that the central bank benefits from lower inflation expectations $\pi_{2}^{e}$. Thus, it has an incentive to improve its reputation through its actions in period one.

In the first period, the central bank uses (2) and (8) to maximize the expected value of its objective function (1) with respect to $i_{1}$ subject to (4) and (3), and given $\pi_{1}^{e}, d_{1}$ and $s_{1}$. But now it also takes into account the effect of $i_{1}$ on $W_{2}$ through $\pi_{2}^{e}$, because the private sector updates its inflation expectations $\pi_{2}^{e}$ using the policy instrument $i_{1}$. This is the crucial mechanism that generates reputation effects. It is assumed that people use the following updating rule, which is shown to be consistent with a rational expectations equilibrium in sections 3.1 and $3.2:^{4}$

$$
\pi_{2}^{e}=u+v i_{1} .
$$

The first order condition with respect to $i_{1}$ implies

$$
i_{1}=\bar{r}+\pi_{1}^{e}-\left(\tau+\beta-\pi_{1}^{e}\right)+d_{1}-s_{1}-\delta \beta v .
$$

This expression for the nominal interest rate is similar to the one for the second period in (5), except for the last term on the right-hand

\footnotetext{
${ }^{4}$ Existence of a rational expectations equilibrium is no problem in this model. This is in contrast to Bernanke and Woodford (1997) where the central bank uses private sector inflation forecasts to infer information about economic disturbances.
} 
side. This term reflects the reputation effect of the interest rate on inflation expectations in the next period.

To proceed it is necessary to distinguish between the regimes of transparency and opacity.

\subsection{Transparency}

In this paper, transparency refers to the publication of central bank forecasts, which provides information on the economic disturbances $d_{t}$ and $s_{t}$ that affect the central bank's behavior. Thus, people are able to infer the central bank's intentions from its actions. It is useful to make a distinction between conditional forecasts that are based on an explicit level (or path) of the interest rate, and unconditional forecasts, which constitute the best estimate given the information that is available but are based on an anticipated interest rate (path) that is not specified.

To see how the publication of conditional central bank forecasts contributes to economic transparency, let $i^{C}$ denote the interest rate that is used for the conditional forecast. Then the public can use the conditional central bank forecast for output $y_{t}^{C}$, its inflation expectations $\pi_{t}^{e}$ and (3) to deduce (the central bank's forecast of) the demand shock $d_{t}$. Similarly, (the central bank's forecast of) the supply shock $s_{t}$ follows from the conditional central bank forecast for inflation $\pi_{t}^{C}, y_{t}^{C}, \pi_{t}^{e}$ and (4). Note that it is generally necessary to disclose forecasts for both output and inflation to identify demand and supply shocks. In contrast to the literature on inflation forecast targeting pioneered by Svensson (1997), output forecasts play an important role for transparency. This may explain why central banks tend to publish inflation as well as output forecasts.

Perhaps surprisingly, the publication of unconditional forecasts does not necessarily have the same effect as that of conditional forecasts, an issue which is briefly discussed in section 3.3. For the rest of the paper, (economic) transparency corresponds to the publication of conditional central bank forecasts. 
Under a regime of transparency, indicated by superscript $T$, the public knows $i_{1}, d_{1}$ and $s_{1}$ when it forms its inflation expectations $\pi_{2}^{e}$. It can therefore infer the inflation target $\tau$ (ex post) from the interest rate $i_{1}$ using (10). Rational expectations and (7) then imply

$$
\left(\pi_{2}^{e}\right)^{T}=\mathrm{E}_{1}^{T}\left[\pi_{2} \mid i_{1}\right]=\tau+\beta,
$$

where moment operators with subscript $t \in\{0,1\}$ and superscripts $R \in\{T, O\}$ are conditional on the information set $\Omega_{t}^{R}$. Substituting (11) into (5), (6) and (7) gives the interest rate, output and inflation in the second period:

$$
\begin{aligned}
i_{2}^{T} & =\bar{r}+\tau+\beta+d_{2}-s_{2} \\
y_{2}^{T} & =\bar{y}+s_{2} \\
\pi_{2}^{T} & =\tau+\beta .
\end{aligned}
$$

To get the outcomes in the first period, the reputation coefficient $v$ must be computed. Under transparency, solving (10) for $\tau$, substituting into (11) and matching coefficients with (9) yields ${ }^{5,6}$

$$
v^{T}=-1 \text {. }
$$

Thus, it is established that this is indeed a rational expectations equilibrium. ${ }^{7}$ The negative value of $v^{T}$ indicates that the central bank can invest in reputation by increasing the nominal interest rate $i_{1}$ to reduce inflation expectations $\pi_{2}^{e}$. The first-period outcomes are obtained by substituting (15) into (10), using (3) and (4), and imposing rational expectations, $\left(\pi_{1}^{e}\right)^{T}=\mathrm{E}_{0}^{T}\left[\pi_{1}\right]$. This produces

$$
\begin{aligned}
i_{1}^{T} & =\bar{r}+\mathrm{E}_{0}^{T}[\tau]-\left(\tau-\mathrm{E}_{0}^{T}[\tau]\right)+(1-\delta) \beta+d_{1}-s_{1} \\
y_{1}^{T} & =\bar{y}+\left(\tau-\mathrm{E}_{0}^{T}[\tau]\right)+s_{1} \\
\pi_{1}^{T} & =\tau+(1-\delta) \beta .
\end{aligned}
$$

${ }^{5}$ For completeness, $u^{T}=\bar{r}+2\left(\pi_{1}^{e}\right)^{T}+\delta \beta+d_{1}-s_{1}$

${ }^{6}$ Note that (11) may give the impression that $v^{T}=0$ is also a solution. However, $\tau$ is not directly observable; it can only be inferred indirectly from $i_{1}, d_{1}$ and $s_{1}$. As a result, $\pi_{2}^{e}$ does depend on $i_{1}$.

${ }^{7}$ Multiple rational expectations equilibria may exist. However, this is the only one that satisfies the McCallum (1983) criterion to employ a minimal set of state variables in the updating equation. 
The first period is different from the second period for two reasons. First, expectations of the inflation target $\tau$ are updated. In the first period, the uncertainty about the central bank's inflation target makes the level of output $y_{1}^{T}$ dependent on the central bank's type $\tau$, because a higher inflation target reduces the interest rate and thereby raises output. But in the second period, transparency has allowed the public to infer the inflation target, so output $y_{2}^{T}$ no longer depends on the central bank's type $\tau$ as $\mathrm{E}_{1}^{T}[\tau]=\tau$.

The second difference is the reputation effect that decreases both the nominal interest rate and inflation in period one. The effect on the interest rate may seem counter-intuitive. However, for a given level of inflation expectations $\pi_{1}^{e}$, the central bank chooses a higher (nominal and ex ante real) interest rate, and thereby lower output and lower inflation, in period one to reduce inflation expectations in period two. The lower level of inflation in period one is anticipated and reduces inflation expectations $\pi_{1}^{e}$. This decreases the (nominal and ex ante real) interest rate. Rational expectations ensure that the negative effect on output in period one is completely offset, so there is no net effect on the ex ante real interest rate. As a result, lower inflation expectations give rise to a lower nominal interest rate in period one. The effect of reputation on inflation is more familiar. Although the ex ante real interest rate is the same, the lower level of inflation expectations $\pi_{1}^{e}$ reduces the level of inflation, partly eliminating the inflationary bias of discretionary monetary policy: $\tau<\pi_{1}^{T}<\pi_{2}^{T}$.

Substituting (11) into (8), and using (18) and (17), the expected payoff to the central bank in the case of transparency equals

$$
\mathrm{E}_{0}^{T}[U \mid \tau]=-\left[(1-\delta)^{2}+\delta\right] \frac{1}{2} \beta^{2}+\beta\left(\tau-\mathrm{E}_{0}^{T}[\tau]\right) .
$$

It shows that the central bank's expected payoff is decreasing in the inflation target expected by the public, $\mathrm{E}_{0}^{T}[\tau]$, which is important for the self-selection effect when the regime is endogenous. 


\subsection{Opacity}

To appreciate the benefits of transparency it is important to look at the case of opacity as well. Under a regime of opacity, indicated by superscript $O$, the public updates its prior on the inflation target $\tau$ from the policy instrument $i_{1}$, although it is no longer able to perfectly infer the central bank's intentions. Use rational expectations, (7), (10) and the fact that $i_{1}$ and $\pi_{2}^{e}$ are jointly normally distributed because of their common dependence on $\tau$, to get

$$
\left(\pi_{2}^{e}\right)^{O}=\mathrm{E}_{1}^{O}\left[\pi_{2} \mid i_{1}\right]=\mathrm{E}_{1}^{O}[\tau]+\frac{\operatorname{Cov}_{1}^{O}\left\{\tau, i_{1}\right\}}{\operatorname{Var}_{1}^{O}\left[i_{1}\right]}\left(i_{1}^{O}-\mathrm{E}_{1}^{O}\left[i_{1}\right]\right)+\beta .
$$

Matching coefficients between (20) and (9) yields ${ }^{8}$

$$
v^{O}=-\frac{\sigma_{\tau}^{2}}{\sigma_{\tau}^{2}+\sigma_{d}^{2}+\sigma_{s}^{2}} \equiv-\lambda,
$$

where $\lambda$ can be interpreted as a signal-to-noise ratio. Note that $0<\lambda<1$, so $\left|v^{O}\right|<\left|v^{T}\right|$. A lower interest rate has a smaller effect on $\pi_{2}^{e}$ under opacity because people cannot tell whether it reflects a weak central bank (high $\tau$ ), or either a negative demand shock (low $d_{1}$ ) or positive supply shock (high $s_{1}$ ). The signal $i_{1}$ is noisier so the optimal response to it is smaller. In the limiting case $\left(\sigma_{d}^{2}+\sigma_{s}^{2}\right) \rightarrow 0$, it follows that $\lambda \rightarrow 1$; the absence of uncertainty about the disturbances $d_{1}$ and $s_{1}$ in period two gives the same outcome for $v$ as under transparency. ${ }^{9}$

Using (10), (20) amounts to

$$
\left(\pi_{2}^{e}\right)^{O}=\tau+\beta-(1-\lambda)\left(\tau-\mathrm{E}_{1}^{O}[\tau]\right)-\lambda\left(d_{1}-s_{1}\right) .
$$

This shows that a positive net demand shock has a beneficial effect on reputation under opacity, because rational agents partly attribute

\footnotetext{
${ }^{8}$ For completeness, $u^{O}=\lambda\left(\bar{r}+2\left(\pi_{1}^{e}\right)^{O}+\lambda \delta \beta\right)+(1-\lambda)\left(\mathrm{E}_{0}^{O}[\tau]+\beta\right)$.

${ }^{9}$ Notice that $\lambda \rightarrow 1$ is not sufficient to get $u^{O}=u^{T}$, and thereby $\left(\pi_{2}^{e}\right)^{O}=\left(\pi_{2}^{e}\right)^{T}$, because of a difference in the information sets at the end of the first period. In particular, $u^{O}$ depends on $\mathrm{E}_{1}^{O}\left[d_{1}\right]=\mathrm{E}_{1}^{O}\left[s_{1}\right]=0$, whereas $u^{T}$ depends on $\mathrm{E}_{1}^{T}\left[d_{1}\right]=d_{1}$ and $\mathrm{E}_{1}^{T}\left[s_{1}\right]=s_{1}$.
} 
the rise in interest rates to a low inflation target $\tau$ and reduce their inflation expectations accordingly. In addition, the central bank enjoys lower inflation expectations $\pi_{2}^{e}$ when its inflation target is higher than expected, because the public believes that the lower level of interest rates is due to negative net demand shocks instead.

The first-period outcomes are obtained by substituting (21) into (10), using (3) and (4), and imposing rational expectations, $\left(\pi_{1}^{e}\right)^{O}=$ $\mathrm{E}_{0}^{O}\left[\pi_{1}\right]$. This produces

$$
\begin{aligned}
i_{1}^{O} & =\bar{r}+\mathrm{E}_{0}^{O}[\tau]-\left(\tau-\mathrm{E}_{0}^{O}[\tau]\right)+(1-\lambda \delta) \beta+d_{1}-s_{1} \\
y_{1}^{O} & =\bar{y}+\left(\tau-\mathrm{E}_{0}^{O}[\tau]\right)+s_{1} \\
\pi_{1}^{O} & =\tau+(1-\lambda \delta) \beta .
\end{aligned}
$$

These expressions are similar to those under transparency, (16), (17) and (18), except that under opacity the discount factor is effectively reduced from $\delta$ to $\lambda \delta$. To facilitate comparison, use the fact that $\mathrm{E}_{0}^{O}[\tau]=\mathrm{E}_{0}^{T}[\tau]$ because the regime is exogenous and independent of the central bank's type. Then, the nominal interest rate in period one is higher than under transparency $\left(i_{1}^{O}>i_{1}^{T}\right)$, but monetary policy is more expansionary in the sense that it leads to higher inflation $\left(\pi_{1}^{O}>\pi_{1}^{T}\right)$. These results can be reconciled by realizing that the level of inflation expectations $\pi_{1}^{e}$ is higher under opacity. For given initial inflation expectations, $\left(\pi_{1}^{e}\right)^{T}=\left(\pi_{1}^{e}\right)^{O}$, the nominal (and ex ante real) interest rate is lower $\left(i_{1}^{O}<i_{1}^{T}\right)$ and output is higher $\left(y_{1}^{O}>y_{1}^{T}\right)$ under opacity. The reason is that higher interest rates do not reduce inflation expectations $\pi_{2}^{e}$ as much under opacity because the signal is considered noisier. So, the reputation effect $v$ of higher interest rates is diminished under opacity, giving rise to more expansionary monetary policy. People anticipate the higher level of inflation so that $\left(\pi_{1}^{e}\right)^{O}>\left(\pi_{1}^{e}\right)^{T}$. Thus, the central bank sets a higher level of the first-period (nominal and ex ante real) interest rate under opacity to contain inflation. Rational expectations ensure that the levels of output are constant across the regimes, so the ex ante real interest rates are the same 
in both cases. Consequently, opacity brings about a higher firstperiod nominal interest rate. Although the ex ante real interest rate is the same in both cases, the higher level of inflation expectations exerts its influence. As a result, opacity leads to higher first-period inflation than transparency: $\tau<\pi_{1}^{T}<\pi_{1}^{O}<\pi_{2}^{T}=\pi_{2}^{O} \cdot{ }^{10}$

It appears that the adoption of transparency affects the strategic incentives of the central bank and makes investment in reputation more fruitful. It allows the public to identify the central bank's efforts to stabilize economic shocks, which produces a more accurate signal of the central bank's type and makes the public's expectations more responsive. Thus, transparency makes it more enticing for the central bank to invest in reputation, which results in a lower inflation bias than under opacity.

The size of the inflation bias under opacity is decreasing in the signal-to-noise ratio $\lambda$. A reduction in the variance of economic shocks, $\sigma_{d}^{2}$ and $\sigma_{s}^{2}$, increases $\lambda$ by diminishing the severity of opaqueness, so it makes the inflation bias smaller. However, a reduction in the ex ante uncertainty about the central bank's inflation target $\sigma_{\tau}^{2}$ decreases the signal-to-noise ratio $\lambda$ and thereby increases the inflation bias. So, greater preference transparency actually makes a situation of economic opacity worse. As a result, a central bank that enjoys higher credibility (lower $\sigma_{\tau}^{2}$ ) has even more to gain from economic transparency. Intuitively, when the public faces less uncertainty about the central bank's type, it pays less attention to the interest rate, which reduces the payoff of investing in reputation and leads to a higher inflation bias under economic opacity. $^{11}$

To complete the analysis of opacity, substitute (22) into (8), and

\footnotetext{
${ }^{10}$ The result that opacity increases the inflation bias is very robust. A sufficient condition is that $v^{T}<v^{O}$ and it is independent of the way inflation expectations are formed.

${ }^{11}$ This result is in sharp contrast to Walsh (1999) who shows that an explicit inflation target reduces the inflation bias when deviations from the target are considered costly.
} 
use (25) and (24) to get the expected payoff for the central bank

$$
\mathrm{E}_{0}^{O}[U \mid \tau]=-\left[(1-\lambda \delta)^{2}+\delta\right] \frac{1}{2} \beta^{2}+(1+(1-\lambda) \delta) \beta\left(\tau-\mathrm{E}_{0}^{O}[\tau]\right) .
$$

Again, the expected payoff is decreasing in the expected inflation target $\mathrm{E}_{0}^{O}[\tau]$.

\subsection{Comparison}

The analysis of opacity above shows that inflation is lower under transparency $\left(\pi_{1}^{T}<\pi_{1}^{O}\right)$ but independent of economic shocks in both cases, and that the expected value of output conditional on the regime is equal $\left(\mathrm{E}_{0}^{T}\left[y_{1}^{T}\right]=\mathrm{E}_{0}^{O}\left[y_{1}^{O}\right]\right)$. This suggests that the public would prefer transparency. For simplicity, assume that the public shares the central bank's objective function. So, there is no principal-agent problem and (2) can be interpreted as a social welfare function. Using (19) and (26), the expected payoffs for the public, which is ignorant of the central bank's inflation target $\tau$, equal

$$
\begin{aligned}
& \mathrm{E}_{0}^{T}[U]=-\left[(1-\delta)^{2}+\delta\right] \frac{1}{2} \beta^{2} \\
& \mathrm{E}_{0}^{O}[U]=-\left[(1-\lambda \delta)^{2}+\delta\right] \frac{1}{2} \beta^{2} .
\end{aligned}
$$

Since $\mathrm{E}_{0}^{T}[U]>\mathrm{E}_{0}^{O}[U]$, it follows that the public always prefers transparency. ${ }^{12}$

However, central banks do not necessarily agree with the desirability of transparency. With an exogenous regime, $\mathrm{E}_{0}^{T}[\tau]=$ $\mathrm{E}_{0}^{O}[\tau]=\bar{\tau}$, so (19) and (26) imply that $\mathrm{E}_{0}^{T}[U \mid \tau]>\mathrm{E}_{0}^{O}[U \mid \tau]$ if and only if $(2-(1+\lambda) \delta) \frac{1}{2} \beta>\tau-\bar{\tau}$. Strong central banks with low inflation targets would be happy to publish their forecasts, whereas weak central banks with sufficiently high inflation targets would rather be enveloped by secrecy. This suggests that if central banks

\footnotetext{
${ }^{12}$ This conclusion even holds for the more general social welfare function $W_{t}^{S}=$ $-\frac{1}{2}\left(\pi_{t}-\bar{\tau}\right)^{2}-\frac{1}{2} \beta^{S}\left(y_{t}-\bar{y}\right)$ and $U^{S}=W_{1}^{S}+\delta^{S} W_{2}^{S}$, where $\beta^{S}>0$ and $0<\delta^{S}<1$.
} 
could choose the regime themselves, strong central banks would have a greater incentive to adopt openness. Endogeneity of the regime is discussed in the next section.

Before continuing, recall that the analysis has focused on the publication of conditional forecasts, which are based on the assumption of a given level of the interest rate. However, the disclosure of unconditional forecasts, which incorporate anticipated changes in the policy instrument, need not have the same effect. In fact, releasing the unconditional forecast for inflation leads to the worst possible outcome.

To understand this it is important to realize that the release of conditional central bank forecasts both reduces the uncertainty about the central bank's inflation target $\tau$, and gives the central bank better incentives to invest in reputation since market expectations are more sensitive to the interest rate. The publication of the unconditional inflation forecast also reduces uncertainty because it directly reveals the inflation target. But, the public does not need the interest rate $i_{1}$ to infer $\tau$, so that the behavioral incentive is absent. As a result, there is no reduction in the inflation bias. ${ }^{13}$

So, the publication of unconditional central bank forecasts could give rise to the full inflation bias. This suggests that it may be desirable to publish conditional forecasts that are based on an explicit interest rate (path) to guarantee the beneficial incentive effects of transparency. ${ }^{14}$

\section{Endogenous Regime}

So far, the analysis was for an exogenous regime of transparency or opacity. However, the regime need not be imposed by the

\footnotetext{
${ }^{13}$ Formally, (10), (3) and (4) give the unconditional central bank forecast for inflation, $\pi_{1}^{U}=\tau+(1+v \delta) \beta$. Since $\mathrm{E}\left[\tau \mid \pi_{1}^{U}\right]=\tau$, it follows that $v=0$ so that $\pi_{1}=\tau+\beta$. In contrast, $\pi_{1}^{C}$ does not depend on $\tau$ as it is not based on the optimizing $i_{1}$.

${ }^{14}$ Tarkka and Mayes (1999) favor the publication of unconditional forecasts. But there is no inflation bias in their model, so behavioral incentives are immaterial.
} 
government but could be chosen by the central bank itself. In fact, central bank transparency in practice typically exceeds formal disclosure requirements. The previous section shows that the regime preferred by the central bank depends on its inflation target $\tau$. In particular, strong central banks favor transparency, whereas weaker types like opacity. But when central banks choose their own regime, the market realizes this and adjusts its beliefs accordingly, so that typically $\mathrm{E}_{0}^{T}[\tau]<\mathrm{E}_{0}^{O}[\tau]$. Thus, there is a signaling effect associated with the transparency regime. Since (19) and (26) reveal that the expected payoff to the central bank is decreasing in the expected inflation target $\mathrm{E}_{0}^{R}[\tau]$, the adjustment of private sector expectations due to the signaling effect makes transparency more desirable and opacity more onerous. In fact, this market feedback from the choice of regime could be so strong that all types of central banks opt for transparency.

The analysis of the model with an endogenous regime is complicated by the fact that outcomes may arise (on or off the equilibrium path) in which not all central bank types select the same regime. This makes the model nonlinear and closed-form solutions for the outcomes under opacity no longer exist. As a result, the linear updating equation (20) no longer holds under opacity. However, it is still possible to tackle the model analytically by substituting $\partial \mathrm{E}_{1}^{O}\left[\pi_{2}^{e} \mid i_{1}\right] / \partial i_{1}$ for $v^{O}$. Appendix A contains the formal analysis of the model with an endogenous regime.

The central bank chooses the regime that produces the highest expected payoff subject to the equilibrium condition that for all central bank types, the market's expectations $\mathrm{E}_{0}^{R}[\tau]$ are consistent with the regime choices that follow from those expectations. When the market's beliefs off the equilibrium path are also restricted to be rational, transparency is the unique pure-strategy perfect equilibrium. ${ }^{15}$ The proof of this result appears in appendix A.

\footnotetext{
${ }^{15}$ Without this restriction, no pure-strategy perfect equilibrium exists. Mixed equilibria, in which some central bank types randomize between transparency and opaqueness, are possible but not considered here.
} 
Intuitively, weak central banks with high inflation targets are inclined to select opacity, because it obscures their true type. But the market realizes that opacity signals high inflation targets, so it harms the central bank's reputation as it increases $\mathrm{E}_{0}^{O}[\tau]$. The corresponding rise in inflation expectations penalizes opaque central banks, which therefore have a greater incentive to be transparent. This causes opaque central banks with the lowest inflation targets $\tau$ to switch to transparency, which means that the remaining opaque central banks face an even stronger inducement to adopt transparency. In the end, market discipline suffices to make every central bank transparent when the regime is endogenous. It should be noted, however, that this conclusion is quite sensitive to the assumptions.

\section{Discussion}

The analysis above shows that transparency in the form of publication of central bank forecasts reduces the inflation bias and that market feedback can induce transparency when the regime is endogenous. This section assesses the robustness of these results and discusses empirical evidence.

The result that greater economic transparency makes inflation expectations more sensitive to policy actions and reduces the inflation bias is very robust. It also holds for a neo-monetarist or new-Keynesian transmission mechanism and also applies to the commonly used objective function $W_{t}=-\frac{1}{2} \alpha\left(\pi_{t}-\pi^{*}\right)^{2}-$ $\frac{1}{2}\left(y_{t}-y^{*}\right)^{2}$, where $y^{*}>\bar{y}$. In addition, the beneficial effect of disclosure of central bank forecasts extends to information about the structure of the economy. Suppose the public is not sure about the level of the long-run real interest rate $\bar{r}$. This makes the nominal interest rate a noisier signal of the central bank's intentions. As a result, inflation expectations become less sensitive to the nominal interest rate which reduces the reputation effect that limits the 
inflation bias. ${ }^{16,17}$

Furthermore, the reputation mechanism formalized in this paper, namely inference based on policy actions, remains relevant for longer horizons when central bank preferences are subject to change, for instance due to new appointments to the monetary policy committee. This means that the beneficial incentive effects found in the two-period model persist over time. In addition, as people gradually learn more about the central bank as time passes, the reduction in preference uncertainty only increases the benefits of transparency about forecasts. As a result, the conclusions are likely to generalize albeit at the cost of analytical tractability, similar to Faust and Svensson (2001) who focus on transparency about control errors and have to resort to simulations to solve their infinite horizon model.

There is anecdotal support for the relevance of the argument that the publication of central bank forecasts has a beneficial incentive effect. For instance, the Bank of England started publishing its forecasts in Inflation Reports in 1993, when monetary policy was still basically set by the Chancellor of the Exchequer. According to King (1997, p. 440), the current Governor of the Bank of England,

"The original objective of the Inflation Report was, it is fair to say, to act as a disciplining device on Government. The Bank's report would set out its views of the likely implications for inflation of decisions taken (or not taken) by the Chancellor."

After an earlier version of the present paper (Geraats 2000) was

\footnotetext{
${ }^{16}$ More precisely, assume that $\bar{r} \sim N\left(\rho, \sigma_{\rho}^{2}\right)$, independently of $\tau, \varepsilon_{t}^{s}$ and $\varepsilon_{t}^{d}$. Then, $v^{O}=-\sigma_{\tau}^{2} /\left(\sigma_{\rho}^{2}+\sigma_{\tau}^{2}+\sigma_{d}^{2}+\sigma_{s}^{2}\right) \equiv-\lambda_{r}$ so that greater uncertainty about the natural real interest rate $\left(\sigma_{\rho}^{2}\right)$ reduces $\lambda_{r}$ and increases the inflation bias.

${ }^{17}$ Model uncertainty could complicate the interpretation of central bank forecasts. For instance, if the public does not know the natural rate of output $\bar{y}$, it may be unable to infer the economic shocks $d_{t}$ and $s_{t}$ from the forecasts of output and inflation. In that case, central bank forecasts need to be supplemented by the central bank's estimate of the natural rate of output to achieve transparency. Such opaqueness about economic models may be due to lack of professional consensus (Cukierman 2002).
} 
circulated, formal empirical evidence on the relation between the disclosure of central bank forecasts and the level of inflation has been presented by Chortareas, Stasavage and Sterne (2002). They use the central bank survey by Fry et al. (2000) to construct a transparency index for 87 countries based on the extent to which central banks publish forecasts. They find that greater transparency reduces average inflation, even after controlling for macroeconomic features, like openness and per capita output, and institutional characteristics, including political instability and central bank independence. The negative relationship between transparency and inflation holds for inflation and monetary targeting frameworks, but not for countries that have abandoned control over monetary policy by adopting an exchange rate peg. This is consistent with the prediction of the present paper that the publication of central bank forecasts improves the incentives for the central bank to reduce the inflation bias.

The result that an endogenous choice of regime leads to transparency is less robust and hinges on several assumptions. First, it requires that the central bank's objective function is linear in output, so that prior expectations $\mathrm{E}_{0}^{R}[\tau]$ enter linearly. Second, it relies on the strong assumption of rationality of market expectations both on and off the equilibrium path. If the public uses Bayesian updating to form its expectations, a situation of secrecy could persist and unravel to the transparency equilibrium only gradually. ${ }^{18}$ Third, there could be bureaucratic or political motives for obfuscation. Like any bureaucracy, central banks may have incentives to hide mistakes or embarrassing forecasts, or to cherish the information rents that secrecy brings, like extensive media attention (see Stiglitz 1999). Or, central bankers may simply find it burdensome to substantiate their decisions. In addition, a central bank that lacks operational inde-

\footnotetext{
${ }^{18}$ Interestingly, the wave of central bank transparency that has emerged over the last two decades began in New Zealand in 1989, which made its central bank subject to a contract (Policy Targets Agreement) and disclosure requirements (Monetary Policy Statements). Its success may have started the Bayesian updating process and triggered greater transparency elsewhere.
} 
pendence or a clear political mandate may envelop itself in secrecy to obtain insulation from political pressures (Geraats 2001). Thus, the movement towards central bank independence during the last few decades may have contributed to the endogenous adoption of transparency by central banks.

A striking feature of the result that the negative market feedback in response to secrecy could induce transparency is that it applies more widely: It holds for any problem in which the expected payoff of an agency of unobservable type $\tau$ equals $\mathrm{E}^{R}[U \mid \tau]=$ $A^{R}\left(\tau-\mathrm{E}^{R}[\tau]\right)+B^{R}$, where $0<A^{T}<A^{O}, B^{O} \leq B^{T}$, and $\tau$ has a normal distribution. Intuitively, the restrictions on the coefficients imply that with transparency, the agency benefits less if its type is different from the market's expectation, and that transparency is not worse than opacity ex ante.

The finding that reputational concerns could provide a sufficiently strong incentive to achieve information disclosure may be useful in other contexts. For instance, the International Monetary Fund (IMF) has established "Codes of Good Practices on Transparency" in monetary, financial and fiscal policies, but does not enforce implementation. Instead, it appears to rely on the hope that lack of adherence is penalized by international financial markets so that countries adopt these standards 'voluntarily'. This paper suggests that reliance on market discipline could indeed enforce transparency (or other international standards). However, if market expectations are not rational off the equilibrium path but instead are determined through Bayesian updating, then a situation of secrecy could prevail for a long time and a stimulus may be required before market feedback starts operating. ${ }^{19}$ A further analysis of these interesting issues is beyond the scope of this paper and left for future research.

Last but not least, there are other effects of transparency besides reputational incentives. For instance, it could affect the stabiliza-

\footnotetext{
${ }^{19}$ The IMF assesses compliance in its "Reports on Observance of Standards and Codes" which are typically published on its web site (http://www.imf.org). This policy of "naming and shaming' could speed up the process of market enforcement.
} 
tion of economic shocks, which need not be beneficial. A further discussion is provided in the survey paper on central bank transparency by Geraats (2002). It shows that the theoretical literature is by no means unequivocal about the benefits of transparency, which may explain why there is still considerable variation in the degree of transparency of monetary policy in practice.

\section{Conclusion}

Transparency has become a key feature of monetary policy and most central banks have adopted the practice of publishing forward looking analysis. This paper analyzes the reputational effects related to transparency of monetary policy, focusing on the publication of central bank forecasts. It shows how such transparency enhances the central bank's ability to build reputation and reduces the inflationary bias of discretionary monetary policy. This may explain why the trendsetters in transparency, the Reserve Bank of New Zealand and the Bank of England, had histories of relatively high inflation. It also shows the importance of transparency for a young central bank, like the European Central Bank. Moreover, the finding that publication of forecasts reduces inflation is consistent with cross-section empirical evidence.

The paper shows that central banks with inflationary preferences are reluctant to adopt transparency since it reveals their true intents. However, when the choice of transparency is endogenous, secrecy signals an inflationary central bank and the public rationally increases its inflation expectations. This harmful effect on the reputation of the central bank makes secrecy less attractive and could provide a sufficient incentive to choose transparency. Such reputational concerns induced by market discipline apply more widely and help to explain why transparency often goes beyond formal disclosure requirements. 


\section{A Appendix: Endogenous Regime}

This Appendix formally analyzes the model when the transparency regime is endogenous. It proves that transparency is the unique, pure-strategy perfect equilibrium when the market's beliefs off the equilibrium path are restricted to be rational.

With an endogenous regime, cases may arise (on or off the equilibrium path) in which some central bank types choose transparency and others opacity. Following the intuition in section 3.3, it is an educated guess that such outcomes feature a threshold $\tilde{\tau}$ such that central banks with $\tau<\tilde{\tau}(\tau>\tilde{\tau})$ prefer transparency (opacity). This conjecture is shown to be correct below. More precisely, $\mathrm{E}_{0}^{T}[U \mid \tilde{\tau}]=$ $\mathrm{E}_{0}^{O}[U \mid \tilde{\tau}]$, and $\mathrm{E}_{0}^{T}[\tau]=\mathrm{E}[\tau \mid \tau<\tilde{\tau}]$ whereas $\mathrm{E}_{0}^{O}[\tau]=\mathrm{E}[\tau \mid \tau>\tilde{\tau}]$. The threshold does not affect the updating under transparency since the inflation target $\tau$ can be inferred perfectly. However, the linear updating rule (20) no longer applies under opacity because $\tau$ has a truncated normal distribution. Let $\phi($.$) denote the probability den-$ sity function of the standard normal distribution and $\Phi($.$) the corre-$ sponding cumulative density function. Then the updating equation under opacity has the expression familiar from truncated regression:

$$
\mathrm{E}_{1}^{O}\left[\tau \mid i_{1}\right]=\mathrm{E}[\tau \mid X, \tau>\tilde{\tau}]=X \xi+\sigma \frac{\phi\left(\frac{\tilde{\tau}-X \xi}{\sigma}\right)}{1-\Phi\left(\frac{\tilde{\tau}-X \xi}{\sigma}\right)},
$$

where $X=\left[1, i_{1}\right], \xi=\left[\mathrm{E}[\tau]-\frac{\operatorname{Cov}\left\{\tau, i_{1}\right\}}{\operatorname{Var}\left[i_{1}\right]} \mathrm{E}\left[i_{1}\right], \frac{\operatorname{Cov}\left\{\tau, i_{1}\right\}}{\operatorname{Var}\left[i_{1}\right]}\right]^{\prime}$ and $\sigma^{2}=$ $\operatorname{Var}\left[\tau \mid i_{1}\right]=\operatorname{Var}[\tau]-\frac{\left(\operatorname{Cov}\left\{\tau, i_{1}\right\}\right)^{2}}{\operatorname{Var}\left[i_{1}\right]}$. Hence, the updating coefficient under opacity equals

$$
v^{O}(\tilde{\tau}) \equiv \frac{\partial \mathrm{E}\left[\tau \mid i_{1}, \tau>\tilde{\tau}\right]}{\partial i_{1}}=\frac{\operatorname{Cov}\left\{\tau, i_{1}\right\}}{\operatorname{Var}\left[i_{1}\right]}\left(1-\left.\frac{\partial}{\partial z} \frac{\phi(z)}{1-\Phi(z)}\right|_{z=\frac{\tilde{\tau}-X \xi}{\sigma}}\right) .
$$

Using (10) this reduces to $v^{O}(\tilde{\tau})=-\left(1-\left.\frac{\partial}{\partial z} \frac{\phi(z)}{1-\Phi(z)}\right|_{z=\frac{\tilde{\tau}-X \xi}{\sigma}}\right) \lambda \equiv$ 
$-\lambda(\tilde{\tau})$. Since $\frac{\phi(z)}{1-\Phi(z)}$ is convex in $z,{ }^{20}$ with a horizontal asymptote of 0 as $z \rightarrow-\infty$ and an asymptote of $z$ as $z \rightarrow \infty$, it follows that $0<\frac{\partial}{\partial z} \frac{\phi(z)}{1-\Phi(z)}<1$ and $0<\lambda(\tilde{\tau})<\lambda<1$. The existence of a threshold makes inflation expectations less sensitive to the interest rate under opacity, because there is relatively less uncertainty about the inflation target. Note that $\lim _{\tilde{\tau} \rightarrow-\infty} \lambda(\tilde{\tau})=\lambda$, which corresponds to opacity under the exogenous regime in section 3.2. To obtain the opacity outcome in threshold cases, simply substitute $\lambda(\tilde{\tau})$ for $\lambda .{ }^{21}$ This means that for a threshold $\tilde{\tau}$, the central bank's expected payoff can be written as

$$
\mathrm{E}_{0}^{R}[U \mid \tau ; \tilde{\tau}]=A^{R}(\tilde{\tau})\left(\tau-\mathrm{E}_{0}^{R}[\tau ; \tilde{\tau}]\right)+B^{R}(\tilde{\tau}),
$$

where $A^{R}$ and $B^{R}$ follow from (19) and (26), so

$$
\begin{aligned}
A^{T} & =\beta \\
A^{O}(\tilde{\tau}) & =(1+[1-\lambda(\tilde{\tau})] \delta) \beta \\
B^{T} & =-\left[(1-\delta)^{2}+\delta\right] \frac{1}{2} \beta^{2} \\
B^{O}(\tilde{\tau}) & =-\left[(1-\lambda(\tilde{\tau}) \delta)^{2}+\delta\right] \frac{1}{2} \beta^{2} .
\end{aligned}
$$

Notice that $0<A^{T}<A^{O}$ and $B^{O}<B^{T}<0$ for any $\tilde{\tau}$. It follows that $\mathrm{E}_{0}^{T}[U \mid \tau ; \tilde{\tau}]$ and $\mathrm{E}_{0}^{O}[U \mid \tau ; \tilde{\tau}]$ are increasing in $\tau$ with slopes $A^{T}$ and $A^{O}$, respectively. As a result, if there exists a threshold $\tilde{\tau}$ such that $\mathrm{E}_{0}^{T}[U \mid \tilde{\tau} ; \tilde{\tau}]=\mathrm{E}_{0}^{O}[U \mid \tilde{\tau} ; \tilde{\tau}]$, then the central bank prefers a regime of transparency (opacity) for $\tau\langle\tilde{\tau}(\tau\rangle$ $\tilde{\tau})$, and rational expectations imply that $\mathrm{E}_{0}^{T}[\tau]=\mathrm{E}[\tau \mid \tau<\tilde{\tau}]$ and $\mathrm{E}_{0}^{O}[\tau]=\mathrm{E}[\tau \mid \tau>\tilde{\tau}]$. Using (27) it is straightforward to show that the normalized threshold inflation target $\tilde{z} \equiv(\tilde{\tau}-\bar{\tau}) / \sigma_{\tau}$ must

\footnotetext{
${ }^{20}$ For a proof that $f(z) \equiv \frac{\phi(z)}{1-\Phi(z)}$ is convex, see Sampford (1953). As a corollary, $f(-z)=\frac{\phi(z)}{\Phi(z)}$ is also convex.

${ }^{21}$ Note that $\lambda(\tilde{\tau})$ implicitly depends on $i_{1}$, so (23) no longer provides a closed-form solution for $i_{1}^{O}$. Although a solution for $i_{1}^{O}$ always exists, it may not be unique. However, the remainder holds for any solution defined by (23).
} 
satisfy $^{22}$

$$
\tilde{z}=\frac{A^{O}(\tilde{\tau})}{A^{O}(\tilde{\tau})-A^{T}} \frac{\phi(\tilde{z})}{1-\Phi(\tilde{z})}+\frac{A^{T}}{A^{O}(\tilde{\tau})-A^{T}} \frac{\phi(\tilde{z})}{\Phi(\tilde{z})}+\frac{B^{T}-B^{O}(\tilde{\tau})}{A^{O}(\tilde{\tau})-A^{T}} \frac{1}{\sigma_{\tau}} .
$$

The proof that transparency is the unique, pure-strategy perfect equilibrium when the market's beliefs off the equilibrium path are restricted to be rational, proceeds in three steps. First, it is shown that there exists no threshold equilibrium in which some central banks decide to adopt transparency and some opacity. Second, it appears that opacity cannot be an equilibrium because central banks with low inflation targets prefer to deviate. Third, it is verified that transparency is indeed an equilibrium.

(I) Suppose that there is a threshold equilibrium such that a central bank with inflation target $\tilde{\tau}$ is indifferent between transparency and opacity. Then the normalized threshold $\tilde{z}$ (if any) satisfies (28). This equation has the structure $\tilde{z}=C_{1} \frac{\phi(\tilde{z})}{1-\Phi(\tilde{z})}+C_{2} \frac{\phi(\tilde{z})}{\Phi(\tilde{z})}+C_{3}$ where $C_{1}>1, C_{2}>0$ and $C_{3}>0$ for any $\tilde{\tau}$; in addition, $C_{1}, C_{2}$, and $C_{3}$ are continuous in $\tilde{\tau}$, with finite limits as $\tilde{\tau} \rightarrow \pm \infty$. Momentarily treating $\tilde{z}$ and $\tilde{\tau}$ as independent variables, $C_{1} \frac{\phi(\tilde{z})}{1-\Phi(\tilde{z})}+C_{2} \frac{\phi(\tilde{z})}{\Phi(\tilde{z})}+C_{3}$ is strictly positive and convex in $\tilde{z}$ as $\phi / \Phi$ and $\phi /(1-\Phi)$ are convex. Furthermore, $C_{1} \frac{\phi(\tilde{z})}{1-\Phi(\tilde{z})}+C_{2} \frac{\phi(\tilde{z})}{\Phi(\tilde{z})}$ has an asymptote of $-C_{2} \tilde{z}$ as $\tilde{z} \rightarrow-\infty$ and $C_{1} \tilde{z}$ as $\tilde{z} \rightarrow \infty$. So, $\tilde{z}<C_{1} \frac{\phi(\tilde{z})}{1-\Phi(\tilde{z})}+C_{2} \frac{\phi(\tilde{z})}{\Phi(\tilde{z})}+C_{3}$ for any $\tilde{z}$ and $\tilde{\tau}$, including $\tilde{\tau}=\sigma_{\tau} \tilde{z}+\bar{\tau}$. Hence, the right-hand side of (28) is strictly greater than $\tilde{z}$ for any $\tilde{z}$. This means that no threshold equilibrium exists.

(II) Now, suppose that opacity is a perfect equilibrium, so $\mathrm{E}_{0}^{O}[\tau]=\bar{\tau}$. Consider whether there exists a threshold $\tilde{\tau}$ such that a central bank is indifferent between opacity and deviating to transparency. Rational expectations imply that $\mathrm{E}_{0}^{T}[\tau]=\mathrm{E}[\tau \mid \tau<\tilde{\tau}]$. Then, the first term on the right-hand side of (28) vanishes, so that

\footnotetext{
${ }^{22}$ Recall that $\tau \sim N\left(\bar{\tau}, \sigma_{\tau}^{2}\right)$, so that $\mathrm{E}[\tau \mid \tau<\tilde{\tau}]=\bar{\tau}-\sigma_{\tau} \phi\left(\frac{\tilde{\tau}-\bar{\tau}}{\sigma_{\tau}}\right) / \Phi\left(\frac{\tilde{\tau}-\bar{\tau}}{\sigma_{\tau}}\right)$ and $\mathrm{E}[\tau \mid \tau>\tilde{\tau}]=\bar{\tau}+\sigma_{\tau} \phi\left(\frac{\tilde{\tau}-\bar{\tau}}{\sigma_{\tau}}\right) /\left[1-\Phi\left(\frac{\tilde{\tau}-\bar{\tau}}{\sigma_{\tau}}\right)\right]$.
} 
it takes the form $\tilde{z}=C_{2} \frac{\phi(\tilde{z})}{\Phi(\tilde{z})}+C_{3}$. Note that $C_{2} \frac{\phi(\tilde{z})}{\Phi(\tilde{z})}$ is decreasing and convex in $\tilde{z}$, with an asymptote of $-C_{2} \tilde{z}$ as $\tilde{z} \rightarrow-\infty$ and 0 as $\tilde{z} \rightarrow \infty$. So, for any $\tilde{\tau}$, including $\tilde{\tau}=\sigma_{\tau} \tilde{z}+\bar{\tau}$, there exists a finite $\tilde{z}$ such that $\tilde{z}=C_{2} \frac{\phi(\tilde{\Phi})}{\Phi(\tilde{z})}+C_{3}$. This implies that a threshold $\tilde{\tau}$ exists so that opacity cannot be a perfect e quilibrium.

(III) Finally, suppose that transparency is a perfect equilibrium, so $\mathrm{E}_{0}^{T}[\tau]=\bar{\tau}$. Consider whether there exists a threshold $\tilde{\tau}$ such that a central bank is indifferent between transparency and deviating to opacity. Rational expectations imply $\mathrm{E}_{0}^{O}[\tau]=\mathrm{E}[\tau \mid \tau>\tilde{\tau}]$. Then, the second term on the right-hand side of (28) vanishes, so that it takes the form $\tilde{z}=C_{1} \frac{\phi(\tilde{z})}{1-\Phi(\tilde{z})}+C_{3}$. Note that $C_{1} \frac{\phi(\tilde{z})}{1-\Phi(\tilde{z})}$ is increasing and convex in $\tilde{z}$, with an asymptote of 0 as $\tilde{z} \rightarrow-\infty$ and $C_{1} \tilde{z}$ as $\tilde{z} \rightarrow \infty$. So, $\tilde{z}<C_{1} \frac{\phi(\tilde{z})}{1-\Phi(\tilde{z})}+C_{3}$ for any $\tilde{z}$ and $\tilde{\tau}$, including $\tilde{\tau}=\sigma_{\tau} \tilde{z}+\bar{\tau}$. This implies that there exists no threshold $\tilde{\tau}$ such that deviation from transparency is preferred. Therefore, transparency is the unique, pure-strategy perfect equilibrium. ${ }^{23}$

Note that this conclusion holds regardless of the degree of opacity, which depends negatively on $\lambda$, with $\lambda=1$ amounting to the transparency case. So, transparency is the equilibrium even when the central bank has the opportunity to choose an opacity regime with $\lambda$ arbitrarily close to one.

\footnotetext{
${ }^{23}$ Without the restriction that beliefs off the equilibrium path $\left(\mathrm{E}_{0}^{O}[\tau]\right)$ are rational, transparency would not be a perfect equilibrium because there would always exist types with sufficiently large $\tau$ that prefer to deviate. This is a consequence of the unbounded support of the distribution of $\tau$.
} 


\section{References}

Backus, D. and Driffill, J. (1985), 'Inflation and reputation', American Economic Review 75(3), 530-538.

Barro, R. J. (1986), 'Reputation in a model of monetary policy with incomplete information', Journal of Monetary Economics 17(1), 3-20.

Barro, R. J. and Gordon, D. B. (1983), 'A positive theory of monetary policy in a natural rate model', Journal of Political Economy 91(1), 589-610.

Bernanke, B. S., Laubach, T., Mishkin, F. S. and Posen, A. S. (1999), Inflation Targeting: Lessons from the International Experience, Princeton University Press, Princeton, New Jersey.

Bernanke, B. S. and Woodford, M. (1997), 'Inflation forecasts and monetary policy', Journal of Money, Credit, and Banking 29(4), 653-686.

Chortareas, G., Stasavage, D. and Sterne, G. (2002), 'Does it pay to be transparent? International evidence from central bank forecasts', Federal Reserve Bank of St. Louis Review 84(4), 99-117.

Cukierman, A. (2001), Accountability, credibility, transparency and stabilization policy in the eurosystem, in C. Wyplosz, ed., 'The Impact of EMU on Europe and the Developing Countries', Oxford University Press, chapter 3, pp. 40-75.

Cukierman, A. (2002), 'Are contemporary central banks transparent about economic models and objectives and what difference does it make?', Federal Reserve Bank of St. Louis Review 84(4), 15-35. 
Cukierman, A. and Meltzer, A. H. (1986), 'A theory of ambiguity, credibility, and inflation under discretion and asymmetric information', Econometrica 54(5), 1099-1128.

Faust, J. and Svensson, L. E. (2001), 'Transparency and credibility: Monetary policy with unobservable goals', International Economic Review 42(2), 369-397.

Faust, J. and Svensson, L. E. (2002), 'The equilibrium degree of transparency and control in monetary policy', Journal of Money, Credit and Banking 34(2), 520-539.

Fry, M., Julius, D., Mahadeva, L., Roger, S. and Sterne, G. (2000), Key issues in the choice of monetary policy framework, in L. Mahadeva and G. Sterne, eds, 'Monetary Policy Frameworks in a Global Context', Routledge, London, pp. 1-216.

Garfinkel, M. R. and Oh, S. (1995), 'When and how much to talk: Credibility and flexibility in monetary policy with private information', Journal of Monetary Economics 35, 341-357.

Geraats, P. M. (2000), 'Why adopt transparency? The publication of central bank forecasts', CEPR Discussion Paper 2582.

Geraats, P. M. (2001), 'Transparency of monetary policy: Does the institutional framework matter?', mimeo, University of Cambridge.

Geraats, P. M. (2002), 'Central bank transparency', Economic Journal 112, F532-F565.

Gersbach, H. (1998), 'On the negative social value of central banks' transparency', mimeo, University of Heidelberg.

Goodfriend, M. (1986), 'Monetary mystique: Secrecy and central banking', Journal of Monetary Economics 17(1), 63-92. 
Jensen, H. (2000), 'Optimal degrees of transparency in monetary policymaking: The case of imperfect information about the cost-push shock', mimeo, University of Copenhagen.

Jensen, H. (2002), 'Optimal degrees of transparency in monetary policymaking', Scandinavian Journal of Economics 104(3), 399-422.

King, M. (1997), 'The inflation target five years on', Bank of England Quarterly Bulletin, November, pp. 434-442.

Kydland, F. E. and Prescott, E. C. (1977), 'Rules rather than discretion: The inconsistency of optimal plans', Journal of Political Economy 85(3), 473-491.

McCallum, B. T. (1983), 'On non-uniqueness in rational expectations models', Journal of Monetary Econonomics 11(2), 139168.

Peek, J., Rosengren, E. S. and Tootell, G. M. B. (1999), 'Is bank supervision central to central banking?', Quarterly Journal of Economics 114(2), 629-653.

Romer, C. D. and Romer, D. H. (2000), 'Federal Reserve information and the behavior of interest rates', American Economic Review 90(3), 429-457.

Sampford, M. R. (1953), 'Some inequalities on Mill's ratio and related functions', Annals of Mathematical Statistics 24(1), 130-132.

Stiglitz, J. (1999), 'On liberty, the right to know, and public discourse: The role of transparency in public life', Oxford Amnesty Lecture, http://www.worldbank.org/html/extdr/extme/oxfordamnesty.pdf. 
Stiglitz, J. E. (2000), 'The contributions of the economics of information to twentieth century economics', Quarterly Journal of Economics 115(4), 1441-1478.

Svensson, L. E. (1997), 'Inflation forecast targeting: Implementing and monitoring inflation targets', European Economic Review 41(6), 1111-1146.

Tarkka, J. and Mayes, D. (1999), 'The value of publishing official central bank forecasts', Bank of Finland Discussion Paper 22/99.

Walsh, C. E. (1999), 'Announcements, inflation targeting and central bank incentives', Economica 66, 255-69.

Winkler, B. (2002), 'Which kind of transparency? On the need for effective communication in monetary policy-making', ifo Studien 48(3), 401-427. 